\title{
Ruínas do desenvolvimento na Região Amazônica Brasileira
}

Ruins of development in the Brazilian Amazon Region

Les ruines $d u$ développement dans la région amazonienne brésilienne

Ruinas del desarrollo en la Amazonía brasileña

\section{Tiago Veloso dos Santos}

\section{(2) OpenEdition}

Journals

\section{Edição electrónica}

URL: https://journals.openedition.org/espacoeconomia/21129

DOI: 10.4000/espacoeconomia.21129

ISSN: 2317-7837

\section{Editora}

Núcleo de Pesquisa Espaço \& Economia

\section{Refêrencia eletrónica}

Tiago Veloso dos Santos, «Ruínas do desenvolvimento na Região Amazônica Brasileira», Espaço e Economia [Online], 22 | 2021, posto online no dia 15 janeiro 2022, consultado o 13 agosto 2022. URL: http://journals.openedition.org/espacoeconomia/21129 ; DOl: https://doi.org/10.4000/ espacoeconomia.21129

Este documento foi criado de forma automática no dia 13 agosto 2022.

\section{c) (i)(2)}

Creative Commons - Atribuição-NãoComercial-Compartilhalgual 4.0 Internacional - CC BY-NC-SA 4.0 https://creativecommons.org/licenses/by-nc-sa/4.0/ 


\title{
Ruínas do desenvolvimento na Região Amazônica Brasileira
}

\author{
Ruins of development in the Brazilian Amazon Region \\ Les ruines du développement dans la région amazonienne brésilienne \\ Ruinas del desarrollo en la Amazonía brasileña
}

Tiago Veloso dos Santos

\section{NOTA DO AUTOR}

Agradeço a Aline Passos (@linpjs) pela generosa interlocução e contínuo incentivo que possibilitou a construção deste texto, nessa forma. Sempre lendo com atenção e divulgando textos que não eram tão bons, mas falavam da Amazônia, região que é mais que uma cartografia desbotada na parede, pois composta de redes de pessoas, lugares e afetos.

\section{Das imagens fora do lugar}

Ao longo da década de 2000, cursei a graduação em Geografia na Universidade Federal do Pará, maior instituição de ensino superior público da Amazônia brasileira. Durante cinco anos, fui apresentado a interpretações diversas da formação do território nacional e, dentre os temas e interpretações desta formação, algumas disciplinas específicas na grade curricular da época que diziam respeito às particularidades da região amazônica, fossem estas particularidades no âmbito da chamada Geografia Física e, portanto, com ênfase em aspectos da biogeografia regional, ou os temas da Geografia Humana, com maior importância as "questões sociais" e suas relações para com aquelas mesmas particularidades.

Nesta trajetória de formação como geógrafo, a Amazônia a qual fui apresentado nas leituras oficiais, fossem estas leituras vindas da maior parte da interpretação acadêmica, através de suas teses e teorias explicativas apreendidas em salas de aula e 
laboratórios, ou fossem apresentadas por autoridades efêmeras nos vários simpósios e eventos a que pude participar, era uma região visualizada a partir de dois ângulos mais fundamentais. O primeiro, como um espaço imageticamente imaginado a partir da premissa da imensidão e exuberância da natureza ${ }^{1}$; o segundo, a partir dos olhares que atentavam para os objetivos, causas e consequências dos ciclos econômicos de modernização da região².

São imagens fortes e recorrentes e que estão presentes nos livros didáticos, nas principais matérias dos veículos de imprensa, no discurso político regional e nacional e; por fim, no senso comum popular. Estas imagens, aceitas e repetidas, possibilitam identificar a estrutura de reconhecimento da região no pensamento social brasileiro e que também está cristalizado na academia mainstraim.

Ao esmiuçar o desdobramento de cada uma dessas imagens, chega-se a duas consequências mais fundamentais. A primeira, a derivação lógico-racional do primeiro imaginário é vislumbrar a Amazônia a partir da suposta infinidade de recursos naturais que devem ser, na melhor das hipóteses, valorizados, conhecidos e preservados dadas as hoje conhecidas restrições ambientais.

A segunda das consequências diz respeito ao papel dos ciclos de modernização que periodicamente pousam na região. Em geral, os ciclos econômicos, são narrados como "frentes de modernização ${ }^{3 ",}$ pois viabilizam a chegada de relações capitalistas, supostamente relações de produção modernas e que teriam o papel de dinamizar a economia regional e integrá-la aos eixos mais dinâmicos em escala nacional ou mundial. Quando esses ciclos se esgotam, pois são episódicos geograficamente e limitados temporalmente, a região retorna à estagnação.

Foi assim com o pequeno ciclo reformista da coroa portuguesa nos oitocentos, dos quais em geral a ideia de modernização política é apresentada no estabelecimento do Diretório dos Índios como o reconhecimento da cidadania, ainda que de segunda classe, das populações tradicionais. 0 encerramento desse momento de incremento econômico foi seguido de um longo período de estagnação, durante o qual criaram-se condições de existência de revoltas populares, tais como a mais conhecida delas, a Cabanagem, na década de $1830^{4}$.

Foi assim no início dos novecentos, com a urbanização das duas maiores cidades da região amazônica, Belém e Manaus, que estavam envoltas pelo excedente de dinheiro advindo da extração da borracha e do trabalho dos seringueiros no interior da floresta ${ }^{5}$. As cidades, que cresceram na época, logo foram tomadas pela tentativa de mimetizar nos trópicos o ideal de civilização. As expressões "pequena Paris" e "Paris dos Trópicos" para designar as reformas urbanas ${ }^{6}$ logo ganharam vida na linguagem das elites. De forma esperada, findo o ciclo, veio uma nova e longa depressão $0^{7}$.

De 1960 em diante, inaugurado um novo ciclo, dessa vez pelo Estado nacional, com a intensificação da integração da região a sociedade e ao território brasileiro, são os "grandes projetos" ${ }^{81}$ que passaram a traduzir essa imagem da chegada da modernidade aos confins da floresta e da civilização.

\section{No campo dos reconhecimentos}

Concluí minha formação como geógrafo e mestre em geografia no final da década de 2010. De lá em diante, passei a atuar como professor e pesquisador na rede de educação básica e superior nas instituições de ensino, o que me permitiu uma certa liberdade de 
movimento na região dada a necessidade de mão de obra. A Amazônia, como demonstram as estatísticas dos censos educacionais ${ }^{9}$, é uma das regiões nas quais a formação de professores há bastante tempo é dependente da educação à distância e mesmo do chamado ensino remoto, ainda que em condições muito precárias de viabilização.

Aproveitei essa liberdade, ainda que precária em termos de recursos, para exercer o ofício de pesquisador que se familiariza com o local empírico de pesquisa, fosse para o desenvolvimento de pesquisas em torno das grandes cidades como Belém, Manaus e São Luís $^{10}$ nas quais me especializei ao longo desse tempo, fosse como orientador de trabalhos de conclusão de curso e ministrando disciplinas e cursos em cidades pelo interior.

Nesta década, percorrendo a região, a Amazônia que conheci em campo e pesquisa é um tanto diferente daquelas interpretações inicialmente apresentadas. Não que elas sejam enganosas ou equivocadas. De fato, os ciclos econômicos e os projetos de integração e desenvolvimento fazem parte da produção do espaço regional, sua grandiosidade estrutural é inegável, os objetivos aos quais estavam ambicionados, integrar a região, foram alcançados. Mas há um elemento menos conhecido e visível na sua área de influência imediata: as ruínas do entorno.

Em uma das primeiras viagens, no ano de 2013, estive em Altamira para ministrar um curso de geografia urbana em formato EaD. A cidade estava em plena expansão por conta da construção da Usina Hidrelétrica de Belo Monte e o debate sobre a cidade antes, durante e após o projeto foi um dos temas das discussões em sala. Após o encerramento da semana de aulas, manifestamos, eu e uma colega de formação, nossa intenção de percorrer a região até a obra, um dos alunos gentilmente se dispôs a nos acompanhar.

O primeiro trajeto da viagem incluía uma estrada de terra saindo do perímetro urbano. Essa estrada era uma composição de uma das mais famosas rodovias do Brasil, a Transamazônica. Em um trecho inicial, registramos ainda presente o tronco da árvore abatida como símbolo da construção rodoviária da integração nacional. Nesse arremedo de tronco, foi fincada uma placa em celebração à "arrancada histórica para conquista do gigantesco mundo verde", inaugurada pelo então General Presidente Emílio G. Médici, no longínquo ano de 1973. 
Figura 01 - Símbolos do arruinamento amazônico

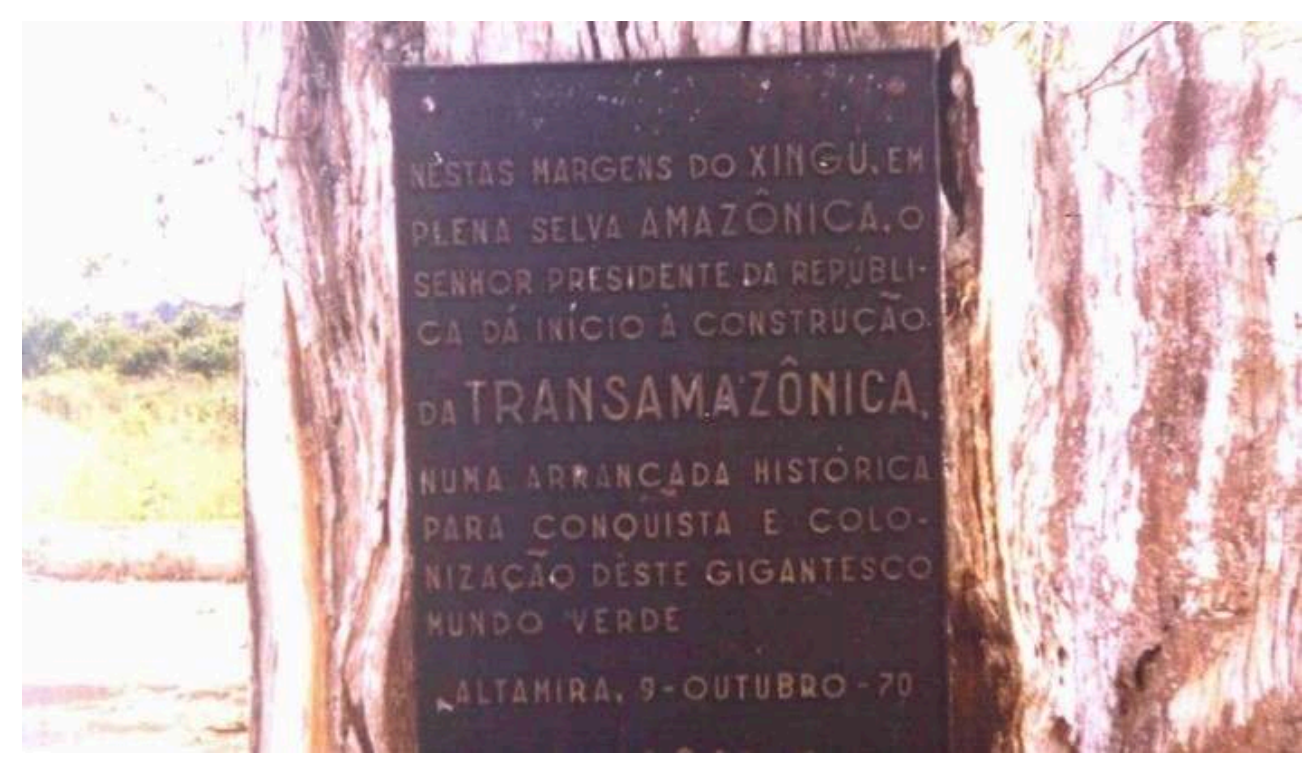

Fonte: o autor (2013)

Continuando o percurso, como havia proibição de adentrar a área de construção pela Norte Energia, consórcio formado para construção da obra, por alegadas razões de segurança, o caminho pelo qual nosso aluno nos levou era cortando algumas estradas paralelas, já na saída de Altamira e adentrando o município de Vitória do Xingu. Chegando na pedreira, no campo externo da Usina Hidrelétrica de Belo Monte, após uma longa manhã por estradas perigosas, empoeiradas e entediantes, a paisagem com a qual nos deparamos era apenas uma variação de tons de cinza. Não era uma paisagem inesperada, mas não deixou de ser um pequeno choque, pois iniciamos nossa viagem pela estrada que prometia "trazer o desenvolvimento" à região, e terminamos em um campo que em nada se diferenciava de um quadro de guerra. Foi a primeira das impressões do arruinamento, não seria última.

Em 2014, organizamos um trabalho de campo com uma turma de licenciandos do curso de Geografia. Nosso destino foi Parauapebas, município do Sudeste do Pará, naquele momento responsável por boa parte da produção mineral brasileira primeiro na pauta de exportações ${ }^{11}$. Saímos de Belém para percorrer os, cerca de, 600 quilômetros que separam a capital da mais rica província mineral do Estado, na qual é extraída o melhor minério de ferro conhecido e levado através de uma ferrovia de 890 quilômetros em direção ao Porto de São Luís e, de lá, direto para o sudeste asiático.

Acampamos no interior da Floresta Nacional de Carajás, em uma visita técnica organizada em conjunto com uma das cooperativas controladas pela VALE, multinacional que opera na região e detém a gestão corporativa do território a partir de seus empreendimentos. $O$ ápice da visita é a observação do mirante da Mina da Serra Nacional dos Carajás, local no qual se consegue observar parte da área minerada. Nos dias seguintes à visita, um dos alunos em um momento de descontração fez um pequeno comentário informal que guardei na memória: "Ah, era grande mesmo, impressionante, mas não deixa de ser apenas um grande buraco".

Em 2015, novo campo com alunos, dessa vez em Tucuruí, município no qual está localizada uma das grandes usinas hidrelétricas construídas no ciclo de integração. Recordo que nesta visita, em particular, eu apenas lembrava de uma outra viagem, feita 
anos antes ao município de Presidente Figueiredo, estado do Amazonas, onde se localiza a usina hidrelétrica de Balbina. A memória foi ativada pelo encontro de dois depoimentos tão distantes quanto semelhantes. Em Tucuruí, um dos técnicos foi perguntado sobre a perda de trabalhadores no momento da construção da obra. $\mathrm{E}$ relatou que não apenas era comum, quanto muitas vezes ignorado pela direção da empreiteira, pois se "caísse um homem lá dentro, não havia muito o que fazer". Foi um depoimento que já havia escutado no lago de Balbina, pelo canoeiro que levou a mim e dois amigos até a proximidade da barragem. São as histórias que se conhecem ao percorrer esses lugares.

Em 2017, recebemos a visita de um grupo de pesquisadores do Sudeste brasileiro. Organizamos um campo ao longo da antiga Estrada de Ferro de Bragança. Essa ferrovia foi um importante modal de transportes construído entre 1880 e 1910, na época da Borracha e foi mantida em operação até os anos $1960^{12}$, quando a região passou a ser cortada pelas rodovias, supostamente vetores de modernização e desenvolvimento. No trajeto, chegamos à antiga ponte de ferro da ferrovia, hoje apenas uma das várias rugosidades daquela época, um objeto que envelheceu pela ausência de sua função original, pois uma das características da modernização na Amazônia é o constante apagamento do passado, ainda que esse passado não esteja tão distante assim pois "Aqui tudo parece que é ainda construção, mas já é ruína", em uma das interpretações antropológicas clássicas sobre o Brasil.

Uma das últimas viagens a campo, antes do advento da pandemia de Covid-19, foi realizada no hoje distante abril de 2019, novamente ao Sudeste do Pará, mas dessa vez com destino a Marabá, passando por Curionopólis e finalizando em Xinguara. A viagem em direção ao I Simpósio Nacional de Geografia Regional, organizado pelos professores do curso de Geografia da Universidade Federal do Sul e Sudeste do Pará (Unifesspa), uma das dezenas de unidades de ensino construídas no processo de expansão e interiorização da educação superior.

Para chegar ao nosso destino, passamos pela "Curva do S", na estrada em Eldorado dos Carajás, onde se localiza o Memorial aos Mártires de Abril do Movimento dos Trabalhadores Rurais Sem Terra (MST), uma das marcas da violência que a modernização deixa em seu caminho, pois a realização desses projetos não seria possível sem a aniquilação de determinados grupos sociais.

Em Curionopólis, município no qual fica localizada a área alagada do Garimpo abandonado de Serra Pelada, conhecemos o relato do massacre dos garimpeiros na década de 1980 pela voz dos personagens que lá estavam e ainda estão. Nessa última viagem ficaram registradas algumas das imagens que me fizeram escrever sobre estes anos.

\section{Chegadas}

Em todas as viagens e reconhecimento das áreas de influência dos projetos era com esse tipo de cenário com os quais me deparei. Pedaços de territórios, fragmentos de destruição, lugares destituídos de memória. De certa forma aqueles "Espaços Quaisquer" que a linguagem deleuziana em Imagem-movimento identificava nas áreas abandonadas, desafetadas, rugosidades de um tempo perdido.

Não havia uma paisagem das promessas de modernização tantas vezes reiteradas nos discursos oficiais e nas interpretações convencionais, quando muito, havia apenas um 
vislumbre provocado por esses atravessamentos de modernização, que sempre era interno aos projetos, nada que espraiasse pelo entorno regional, como era a hipótese de uma famosa teoria econômica francesa testada nos vários "polos de desenvolvimento" da Amazônia ${ }^{13}$. Esses polos nunca foram pontos que irradiavam luminosidade ao seu entorno, ao contrário, disseminaram apenas opacidade.

O conhecimento empírico das imediações apenas reforçava a imagem de que aqueles objetos nada mais são do que fixos dos sistemas de engenharia, com objetivo de viabilizar não apenas a fluidez de capital para a região, mas o seu contrário, a extração da energia vital dos povos e dos territórios em que os recursos estão localizados. Daí o padrão de arruinamento se repetir por tantos lugares e tempos distintos pela região.

Pensar outras formas de preservação da Amazônia passa necessariamente por constituir um vocabulário específico sobre as heranças que estes artefatos estão deixando por toda Amazônia. Os locais que rodeiam estes grandes objetos ${ }^{14}$, hoje poderiam ser denominados de ruínas do desenvolvimento.

\section{BIBLIOGRAFIA}

AB'SABER, A. A cidade de Manaus. In: (Org.). Amazônia: do discurso à práxis. São Paulo: EDUSP, 2004. p. 201-222.

AB'SABER, A. N. Macrodomínio amazônico. In: Os Domínios de natureza no Brasil: potencialidades paisagísticas. São Paulo: Atelie Editorial, 2003.

ACEVEDO MARIN, R. E. Civilização do rio, civilização da estrada: transportes na ocupação da Amazônia no século XIX e XX. In: SITREAMA, I, 2002, Belém. Anais...Belém, n/p, cópia impressa. AGASSIZ, Louis e AGASSIZ, Elizabeth Cary. Viagem ao Brasil: 1865-1866. Brasília: Ed. Senado Federal, 2000.

Amazônia: do discurso à práxis. São Paulo: EDUSP, 2004.

BENJAMIN, W. Obras escolhidas: magia e técnica, arte e política. São Paulo: Brasiliense, 1993.

BECKER, Bertha. Amazônia. São Paulo: Ática, 1990.

Fronteira e urbanização repensadas. Revista Brasileira de Geografia (RBG). Rio de Janeiro, n. 47, 1985, p. 357-371, jul./dez. 1985.

Revisão das políticas de ocupação da Amazônia: é possível identificar modelos para projetar cenários? Parcerias Estratégicas. Brasília, n. 12, 2001, p. 135-159.

Geopolítica da Amazônia: conferência. Universidade de São Paulo: Instituto de Estudos Avançados, 2004.

BECKER, B.; STENNER, C. Um futuro para a Amazônia. São Paulo: Oficina de Textos, 2008.

COELHO, M. C. N; SIMONIAN, L.; FENZL, n. (org.) Estado e política pública na Amazônia: gestão de Recursos naturais. NAEA_UFOA. Ed CEJUP. Belém. 2000. 
COSTA, F. A. Lugar e significado da gestão pombalina na economia colonial do Grão-Pará. Nova Economia, v. 20, nำ 1. Belo Horizonte, 2010.

DEAN, W. A luta pela borracha no Brasil: um estudo de história ecológica. São Paulo: Nobel, 1989.

FERNANDES, D. A. A questão regional e a formação do discurso desenvolvimentista na Amazônia. Belém: Universidade Federal do Pará, 2011.

FURTADO, C. Formação Econômica do Brasil. São Paulo: Companhia das Letras, 2007.

DELEUZE, Gilles. A imagem movimento. Editora 34, 2018.

GONÇALVES, Carlos Walter Porto. Amazônia, amazônias. São Paulo: Contexto, 2001.

LOUREIRO, Antonio José Souto. A Grande Crise (1909-1916). Manaus: edição do autor, 1986.

MAGALHÃES, S; BRITTO, R. C; CASTRO, Edna (org.). Energia na Amazônia. Belém: MPEG / UFPA/ UNAMAZ. 1996.

MALHEIRO, Bruno. Colonialismo Interno e Estado de Exceção: a "emergência" da Amazônia dos Grandes Projetos. Caderno de Geografia, v.30, n.60, 2020.

MALHEIRO, Bruno; PORTO-GONÇALVES, Carlos Walter; MICHELOTTI, Fernando. Horizontes amazônicos: para repensar a Amazônia e o mundo. Rio de Janeiro: Expressão Popular, 2021.

MARENGO, J. A. Mudanças Climáticas Globais e Seus Efeitos sobre a Biodiversidade. Brasília: Ministério do Meio Ambiente, Biodiversidade 26, 2006.

MARTINS, J. S.

MELO, N. A. Políticas territoriais na Amazônia. SP:ANNABLUME, 2006.

MIGNOLO, W. D. Histórias locais / Projetos globais. Belo Horizonte: Editora da UFMG, 2003. $505 \mathrm{p}$.

MIRANDA, R. R. Interfaces do rural e do urbano em área de colonização antiga na Amazônia: estudo de colônias agrícolas em Igarapé-Açu e Castanhal (PA). Programa de Pós-graduação em Geografia, Universidade Federal do Pará, 2009.

NOBRE, C. A.; Obregón, G. O.; Marengo, J. A. Características do Clima Amazônico: Aspectos Principais. Cachoeira Paulista, Brasil: Centro de Ciências do Sistema Terrestre, Instituto Nacional de Pesquisas Espaciais (INPE), 2008.

OLIVEIRA, J. A. Espaço-Tempo de Manaus: a natureza das águas na produção do espaço urbano. ESPAÇO E CULTURA, UERJ, RJ, nº 23, pp. 33-41, JAN./JUN. DE 2008.

PRADO JÚNIOR, C. História Econômica do Brasil. São Paulo: Editora Brasiliense, 2006.

PERROUX, François. O conceito de polos de crescimento. In: FAISSOL, S. (Org.). Urbanização e regionalização: relações com o desenvolvimento econômico. Rio de Janeiro: IBGE, 1975. p. 99-110.

SANTOS, Milton. Os grandes projetos: sistema de ação e dinâmica espacial. In: CASTRO, Edna; MOURA, Edila; MAIA, Maria Lúcia (Orgs.). Industrialização e grandes projetos: desorganização e reorganização do espaço. Belém: EDUFPA, 1995. p. 13 - 20. Promovidos pelo Núcleo de Altos Estudos Amazônicos (NAEA) da Universidade Federal do Pará e pela Associação Nacional de PósGraduação e Pesquisa em Planejamento Urbano e Regional (Anpur).

SANTOS, Roberto. História Econômica da Amazônia: 1800-1920. São Paulo: T.A. Queiroz. 1980. 
SIOLI, H. Amazônia: fundamentos da ecologia da maior região de florestas tropicais. Petrópolis: Vozes, $2^{\text {a }}$ ed. 1990.

VENTURA NETO, R. S. A (Trans)formação socioespacial da Amazônia: Floresta, rentismo e periferia. Instituto de Economia, Universidade Estadual de Campinas, 2017, 297p.

WEINSTEIN, B. A Borracha na Amazônia: Expansão e Decadência (1850-1920). São Paulo: EDUSP, 1993.

\section{NOTAS}

1. Derivam dessa imagem a relativamente extensa lista de substantivos e adjetivos que buscam uma caracterização metafórica da região: "Hiléia", "Inferno Verde”, “El Dorado", "Pulmão do Mundo", etc.

2. É o que ocorre na literatura especializada e mais disseminada sobre a região a partir da segunda metade do século XX, após o estabelecimento das políticas de integração nacional e desenvolvimento regional, objetos de análises das ciências humanas e sociais.

3. Em alusão aos conceitos sociológicos de "frentes de expansão" e "frentes pioneiras".

4. A revolta, entre 1835 e 1840, teve fortes consequências políticas e sociais. Por um lado, provocou um decréscimo populacional na região, tanto pelas batalhas ocasionadas no período das lutas, quanto pelas posteriores perseguições do Estado Imperial brasileiro aos revoltosos no período da "pacificação". Houve ainda repercussões políticas. A Província do Grão-Pará, que já havia sido o último estado a aderir a independência do Brasil em relação a Portugal recebeu punições pela Monarquia brasileira. Vista pelo poder imperial como uma "Colônia popular, indianizada, subversiva, independentista e arrivista" (Lima, 2009), passou a perder gradativamente seu status. Calcula-se que de 30 a $40 \%$ de uma população estimada de 100 mil habitantes morreu.

5. A força de trabalho regional estava majoritariamente organizada em torno de um sistema de trabalho tradicional desde tempos coloniais, o aviamento, que se consolidou a partir do contato da economia amazônica com o sistema monetarizado do capitalismo industrial europeu. As especificidades históricas como a base de recursos naturais - espacialmente ampla e de difícil acesso - o atraso nas técnicas de produção, a ausência de um sistema monetário no circuito do trabalho e a presença de lideranças mercantis locais, que fornecessem créditos ao sistema extrativista ajudaram a fundir as duas características ao longo do tempo e do espaço na organização das atividades econômicas na região, tornando a exploração do trabalho mais eficiente em meio as condições sociais e ambientais de produção.

6. As reformas urbanas em Belém e Manaus foram reflexos de mudanças estruturais e dinâmicas conjunturais e estabeleceram um projetar urbano dessas cidades a partir de uma série de obras e projetos de embelezamento urbano e instalação de redes de serviços públicos, mimetizando o ideário urbanístico inspirado na Paris novecentista.

7. A maior parte da historiografia regional e nacional trata o período que vai do final do colapso gomífero, por volta de 1920, até a chegada dos projetos de desenvolvimento da década de 1960 como um período de profunda estagnação econômica e decadência regional. Na história econômica e social brasileira, autores como Caio Prado Júnior e Celso Furtado descrevem o ciclo da Borracha como um "castelo de cartas em que se fundava toda a prosperidade fictícia" (PRADO JÚNIOR, 2006, p. 240) e como consequência após o seu declínio há uma verdadeira "prostração da economia amazônica" (FURTADO, 2007).

8. A denominação Grandes projetos tornou-se padrão para caracterizar os grandes empreendimentos (econômicos, logísticos, infraestruturais) que não prescindem de espaços urbanos relativamente bem estruturados para o seu funcionamento. 
9. A falta de professores em nível da educação básica é um gargalo, como aponta o Relatório intitulado "Escassez dos professores do Ensino Médio: propostas estruturais e emergenciais", o déficit de professores da educação básica no Brasil em 2007 era de 300 mil, sendo que a tendência até aquele momento era negativa. Dados do Instituto Nacional de Estudos Educacionais (INEP), segundo o mesmo relatório, apontam para uma necessidade de cerca de 235 mil professores para o Ensino Médio no país, conforme mostra a Tabela a seguir:

10. As pesquisas resultaram em uma tese de doutorado intitulada "Metrópoles amazônicas: trajetórias do planejamento e da gestão metropolitana em Belém, Manaus e São Luís", apresentada no ano de 2015 no âmbito do Núcleo de Altos Estudos Amazônicos da Universidade Federal do Pará (NEA/UFPA), além de artigos que podem ser consultados através do CV lattes do autor:

11. No início da década de 2010, em virtude da elevação dos preços de commodities minerais, Parauapebas chegou a responder por $45 \%$ do PIB industrial do estado do Pará.

12. A Estrada de Ferro Belém - Bragança, simbolizou o anseio de modernização da época através da introdução da locomotiva a vapor, ícone tecnológico do século XIX, como meio de transporte para integrar os núcleos agrícolas e escoar a produção até Belém (MIRANDA, 2009). A Ferrovia era o meio que possibilitava a finalidade de colonização empreendida entre Belém e a região da Bragantina, situada a cerca de 210 quilômetros da capital. Desestruturada na década de 1960, quando a opção rodoviarista passou a hegemonizar o transporte na região com a construção da Belém - Brasília. Na Amazônia a introdução de ferrovias se deu entre 1870 e 1880 . Suas construções mais importantes foram a Madeira-Mamoré (fronteira com a Bolívia), cujo objetivo era ligar as áreas produtoras de látex e escoar a produção; a Estrada de Ferro Tocantins, cujo plano era articular Belém à capital goiana; além da Estrada de Ferro Bragança (EFB) (ACEVEDO, 2002).

13. O Polamazônia foi um dos programas de desenvolvimento da ditadura com inspiração na teoria francesa dos "polos de crescimento econômico", de François Perroux. Teve como objetivo a implantação de polos agrícolas, minerais e industriais que permitissem fixação populacional, formando zonas de integração e estimulando a concentração de capitais nos espaços de ocupação. As localidades inseridas recebiam créditos e subsídios fiscais para fixação dos projetos. Mesmo após o encerramento do Polamazônia, a teoria dos polos influenciou a manutenção do Programa "Grande Carajas", nos anos 1980.

14. Em 1991, participando de um evento científico da Associação Nacional de Pós-graduação e Pesquisa em Planejamento Urbano e Regional (ANPUR), sediado no Núcleo de Altos Estudos Amazônicos em Belém do Pará, o professor Milton Santos cunhou a ideia dos "grandes projetos", para denominar os empreendimentos de engenharia característicos dos programas de integração e desenvolvimento.

\section{RESUMOS}

Este é um relato pessoal de uma trilha de pesquisa, construído a partir de um conjunto de trabalhos e visitas de campo pela Amazônia brasileira, realizados ao longo da década de 2010 (2011-2020), e que resultaram para além de pesquisas institucionalizadas e publicadas, em impressões e reflexões a partir das interpretações teóricas e evidências empíricas do pensamento geográfico brasileiro sobre a região. 
This is a personal account of a research trail, built from a set of works and field visits across the Brazilian Amazon, carried out throughout the 2010s (2011-2020), and that resulted, in addition to institutionalized and published research, in impressions and reflections based on theoretical interpretations and empirical evidence of Brazilian geographical thought about the region.

Il s'agit d'un récit personnel d'un ensemble de travaux de terrain au milieu de l'Amazonie brésilienne pendant la période 2011-2020. Cet article est le résultat de nos impréssions et réflexions, ainsi que de la lecture de quelques ouvrages géographiques sur la région.

Este es un relato personal de una ruta de investigación, construida a partir de un conjunto de trabajos y visitas de campo en la Amazonía brasileña, realizadas a lo largo de la década de 2010 (2011-2020), y que resultó, además de investigaciones institucionalizadas y publicadas, en impresiones y reflexiones basadas en interpretaciones teóricas y evidencias empíricas del pensamiento geográfico brasileño sobre la región.

\section{ÍNDICE}

Keywords: Amazon; Amazon devastation; large investment projects; mining; hydroelectric plants

Palavras-chave: Amazônia; devastação amazônica; grandes projetos de investimentos; mineração; hidrelétricas.

Mots-clés: Amazonie; la dévastation amazonienne ; grands projets d'investissement; exploitation des mines; centrales hydroélectriques

Palabras claves: Amazonas; devastación amazónica; grandes proyectos de inversión; minería; centrales hidroeléctricas.

\section{AUTOR}

\section{TIAGO VELOSO DOS SANTOS}

Professor do Instituto Federal de Educação, Ciência e Tecnologia do Pará. E-mail:

tiago.veloso@ifpa.edu.br 